\title{
Bacterial flagellin elicits widespread innate immune defense mechanisms, apoptotic signaling, and a sepsis-like systemic inflammatory response in mice
}

Joëlle Rolli ${ }^{1}$, Noureddine Loukili', Sandra Levrand ${ }^{1}$, Nathalie Rosenblatt-Velin², Stéphanie Rignault-Clerc ${ }^{2}$, Bernard Waeber ${ }^{2}$, François Feihl ${ }^{2}$, Pal Pacher ${ }^{3}$, Lucas Liaudet ${ }^{{ }^{*}}$

\begin{abstract}
Introduction: Systemic inflammation in sepsis is initiated by interactions between pathogen molecular motifs and specific host receptors, especially toll-like receptors (TLRs). Flagellin is the main flagellar protein of motile microorganisms and is the ligand of TLR5. The distribution of TLR5 and the actions of flagellin at the systemic level have not been established. Therefore, we determined TLR5 expression and the ability of flagellin to trigger prototypical innate immune responses and apoptosis in major organs from mice.

Methods: Male Balb/C mice $(n=80)$ were injected intravenously with 1-5 $\mu$ g recombinant Salmonella flagellin. Plasma and organ samples were obtained after 0.5 to $6 \mathrm{~h}$, for molecular investigations. The expression of TLR5, the activation state of nuclear factor kappa B (NF $\kappa$ B) and mitogen-activated protein kinases (MAPKs) [extracellular related kinase (ERK) and c-jun-NH2 terminal kinase (JNK)], the production of cytokines [tumor necrosis alpha (TNF $\alpha$ ), interleukin-1 $\beta$ (IL-1 $\beta$ ), interleukin-6 (IL-6), macrophage inhibitory protein-2 (MIP-2) and soluble triggering receptor expressed on myeloid cells (TREM-1)], and the apoptotic cleavage of caspase-3 and its substrate Poly(ADP-ribose) polymerase (PARP) were determined in lung, liver, gut and kidney at different time-points. The time-course of plasma cytokines was evaluated up to $6 \mathrm{~h}$ after flagellin.

Results: TLR5 mRNA and protein were constitutively expressed in all organs. In these organs, flagellin elicited a robust activation of NF $\kappa$ B and MAPKs, and induced significant production of the different cytokines evaluated, with slight interorgan variations. Plasma TNF $\alpha$, IL-6 and MIP-2 disclosed a transient peak, whereas IL-1 $\beta$ and soluble TREM-1 steadily increased over $6 \mathrm{~h}$. Flagellin also triggered a marked cleavage of caspase- 3 and PARP in the intestine, pointing to its ability to promote significant apoptosis in this organ.

Conclusions: Bacterial flagellin elicits prototypical innate immune responses in mice, leading to the release of multiple pro-inflammatory cytokines in the lung, small intestine, liver and kidney, and also activates apoptotic signalling in the gut. Therefore, this bacterial protein may represent a critical mediator of systemic inflammation and intestinal barrier failure in sepsis due to flagellated micro-organisms.
\end{abstract}

\footnotetext{
* Correspondence: lucas.liaudet@chuv.ch

'Department of Intensive Care Medicine, University Hospital Medical Center and Faculty of Biology and Medicine, rue du Bugnon 46, Lausanne 1010,

Switzerland

Full list of author information is available at the end of the article
} 


\section{Introduction}

Systemic inflammation and multiple organ dysfunction during Gram-negative sepsis have been largely attributed to the activation of innate immune defenses by lipopolysaccharide (LPS) [1]. Accordingly, recent studies showed that strategies interfering with LPS-dependent signaling, including myeloid-differentiation factor-2 [2] and tolllike receptor (TLR) 4 (TLR4) [1] proved beneficial in experimental Gram-negative sepsis. In addition to LPS, most enteric Gram-negative bacteria also release substantial amounts of flagellin, the main structural protein from the bacterial flagellum [3]. Flagellin binds to TLR5 [4] and activates the pro-inflammatory transcription factor nuclear factor $(\mathrm{NF} \kappa \mathrm{B})$ in various epithelial cells, endothelial cells and leukocytes in vitro (see [3] for review). In vivo, the flagellin-TLR5 axis has been associated with the development of cardiovascular collapse [5], acute lung inflammation [6] and inflammatory bowel diseases [7] in mice. Importantly, significant concentration of flagellin circulate in the plasma of human patients with Gram-negative sepsis [6], suggesting that it might represent a significant pro-inflammatory bacterial protein in this setting.

Therefore, the present study was designed to determine the distribution of TLR5 in major organs of mice (lung, liver, kidney and intestine), and to evaluate the ability of these organs to mount an innate immune response to exogenously administered recombinant flagellin. Our main findings indicate that TLR5 is expressed by all the organs examined, and that flagellin elicits prototypical immune signaling in these organs, characterized by the activation of NF $\kappa \mathrm{B}$ and mitogenactivated protein kinases (MAPKs), as well as the production of multiple inflammatory cytokines, and also that flagellin initiates proapoptotic responses predominantly in the intestine. Thus, flagellin/TLR5 signaling elicits several mechanisms that are instrumental in the pathophysiology of sepsis, and might therefore represent a novel target for therapeutic intervention.

\section{Materials and methods}

\section{Administration of flagellin to conscious mice}

All procedures conformed to the Swiss laws on the care and use of laboratory animals and were approved by our local ethical committee for animal experimentation. Male BALB/c mice (weighing 23 to $26 \mathrm{~g}$ ) were injected (tail vein) with recombinant Salmonella muenchen flagellin (Calbiochem, San Diego, CA, USA), given at doses of 1 or $5 \mu \mathrm{g} /$ mouse. Such doses are pathophysiologically and clinically relevant, because free flagellin, at up to several hundred $\mu \mathrm{g} / \mathrm{L}$, is detectable in the plasma of rats with lethal Gram-negative bacteria-induced peritonitis [5], and free flagellin circulates at levels between 2 and
$20 \mu \mathrm{g} / \mathrm{L}$ in the blood of patients with Gram-negative sepsis [6]. Flagellin was suspended in a volume of $0.2 \mathrm{ml}$ isotonic saline. Sham animals injected with saline only were used for control purposes. The flagellin preparation was devoid of LPS contamination, as indicated by the Limulus assay $(<0.0003 \mu \mathrm{g}$ LPS/ $\mu$ g flagellin). At selected time-points (30 minutes to 6 hours), mice were sacrificed by pentobarbital overdose, and the lung, liver, small intestine and kidney were removed for subsequent analyses. Plasma was collected for the measurement of cytokines.

\section{RNA Isolation, RT-PCR and quantitative real-time PCR}

Total RNA from tissues was isolated by TRIzol reagent (Invitrogen, Basel, Switzerland). RNA was reverse-transcribed to cDNA and amplified by PCR (One-step RTPCR kit from Qiagen, Hombrechtikon, Switzerland). A kit of mouse-specific PCR primers was purchased for TLR5 (R\&D Systems, Minneapolis, MN, USA). GAPDH was used for control purposes. The cDNAs were further subjected to quantitative real-time PCR using the SYBR Premix Ex Taq (Takara Bio Inc., Otsu, Shiga, Japan) on a LightCycler Instrument (Roche Applied Science, Rotkreuz, Switzerland). Cycling conditions consisted of an initial denaturating step at $95^{\circ} \mathrm{C}$ (20 seconds) followed by 45 cycles of a thermal step protocol consisting of $95^{\circ}$ $\mathrm{C}$ (30 seconds), $60^{\circ} \mathrm{C}$ (20 seconds). Primer sequences for TLR 5 were 5'-CCA CCG AAG ACT GCG ATG A-3' and 5'-GTG ACC GTG CAC AGG ATG AA-3'. The data obtained for TLR5 were normalized to the level of 18 S (5'-ACT TTT GGG GCC TTC GTG TC-3'; 5'GCC CAG AGA CTC ATT TCT TCT TG-3'), and expressed in fold augmentation with respect to the expression in the kidney (which had the weakest expression).

\section{Protein extraction and immunoblot analyses}

Tissues were homogenized in ice-cold lysis buffer, and cytoplasmic and nuclear proteins were obtained as described [8]. Proteins $(20$ to $80 \mu \mathrm{g})$ were separated by a standard SDS-PAGE procedure. The following antibodies were used for immunoblotting: anti-inhibitor of kappaB alpha $(\mathrm{I} \kappa \mathrm{B} \alpha)$, anti-phospho- $\mathrm{I} \kappa \mathrm{B} \alpha$, anti-c-jun$\mathrm{NH} 2$ terminal kinase (JNK)1, anti-extracellular related kinase (ERK)1/2 (all from Santa-Cruz Biotechnology, Santa Cruz, CA, USA), anti-phospho-JNK1/2, anti-phospho-ERK1/2, anti-poly(ADP-ribose) polymerase (PARP), anti-caspase-3, anti-cleaved-caspase-3 (all from Cell Signaling, Beverly, MA, USA), anti- $\beta$-actin, anti- $\alpha$-tubulin (Sigma-Aldrich, Basel, Switzerland) and anti-TLR5 (Biovision Inc., Mountain View, CA, USA). The immunoblot signals were visualized using enhanced chemiluminescence (ECL, Amersham Biosciences, Otelfingen, Switzer- 
land). Densitometric analysis was performed using a Personal Densitometer TM (Molecular Dynamics, Sunnyvale, CA, USA) and TotalLab software (TotalLab, Newcastle upon Tyne, UK), as described [9].

\section{Electromobility shift assay}

Electromobility shift assay (EMSA) was performed as described [8], by incubating $10 \mu \mathrm{g}$ of nuclear proteins with an NF $\kappa \mathrm{B}$ oligonucleotide probe (5'-GGCAGTTGAAGGGGACTTTCCCAGG-3') labeled with $\alpha$ -

${ }^{32} \mathrm{PdCTP}$, and poly dIdC for 20 minutes. For supershift assays, the nuclear extracts were preincubated for 30 minutes on ice with an anti-p65 or an anti-p50 antibody (both from Cell Signaling, Beverly, MA, USA) before adding the radioactive probe. Samples were resolved on a non-denaturing polyacrylamide gel. Gels were transferred to Whatman $3 \mathrm{M}$ paper (Fisher Scientific, Wohlen, Switzerland), dried under vacuum, and exposed to photographic film at $-70^{\circ} \mathrm{C}$ with intensifying screens.

\section{Quantification of cytokine production}

The tissue concentrations of TNF $\alpha$, IL- $1 \beta$, IL-6, macrophage-inhibitory protein (MIP)-2 and soluble triggering receptor expressed on myeloid cells (sTREM-1) were measured in tissue homogenates using commercially available ELISA kits (R\&D Systems, Minneapolis, MN, USA) according to manufacturer's protocol. The same cytokines were also measured in plasma.

\section{Presentation of data and statistical analysis}

All graphs summarize the results of at least three independent experiments, and are presented as means \pm standard error of the mean. In experiments comparing only two conditions, statistical analysis was performed with Student's $t$ test. In experiments using multiple conditions, comparison was performed with analysis of variance. When the $\mathrm{F}$ value was significant at the $5 \%$ level, further pair-wise comparisons were made between flagellin and control conditions using Dunnett's test. A $P$ value less than 0.05 was considered significant.

\section{Results and discussion}

\section{TLR5 is expressed in mouse lung, liver, small intestine} and kidney

The specific mammalian ligand of flagellin is TLR5 [4]. Our first aim was thus to determine the tissue expression of TLR5 in mice. As illustrated in Figure 1, both TLR5 mRNA (Figures 1a and 1b) and protein (Figure 1c) were detected in all organs evaluated, implying their ability to sense extracellular flagellin. These observations extend previous works, including our own, which identified TLR5 mRNA in various mammalian tissues [10], and TLR5 protein expression in the intestine [7] and myocardium [11]. Of note, quantitative PCR indicated that TLR5 mRNA expression was highest in the lung and liver. Such a high degree of TLR5 expression might be essential for the early detection of invading air-borne or blood-borne flagellated micro-organisms, as proposed previously [12]. Another finding was that TLR5 expression did not increase up to three hours after the administration of flagellin (as evaluated in the lung, Figure 1d), pointing to the lack of inducibility of TLR5 in the presence of its ligand.

\section{Flagellin diffusely activates $\mathrm{NF} \kappa \mathrm{B}$ and MAP kinase signaling in tissues}

The widespread expression of TLR5 indicates that the examined organs might have the ability to mount innate immune defense mechanisms upon the recognition of circulating flagellin. It is known that TLR-dependent immune responses mostly rely on the activation of the key transcription factor $\mathrm{NF} \kappa \mathrm{B}$, a family of dimeric transcription factors, normally held in the cytoplasm of quiescent cells, bound to an inhibitory protein, $\mathrm{I} \kappa \mathrm{B} \alpha$ [13]. NF $\kappa \mathrm{B}$ activation relies on stimulus-induced $\mathrm{I} \kappa \mathrm{B} \alpha$ phosphorylation and proteasomal degradation, allowing free $\mathrm{NF} \kappa \mathrm{B}$ to translocate into the nucleus and to bind to its response element on the DNA [13]. As shown in Figure 2, flagellin $(1 \mu \mathrm{g} /$ mouse $)$ induced significant $\mathrm{I} \kappa \mathrm{B} \alpha$ phosphorylation and degradation after 30 minutes in the different tissues examined. In the lung, the degradation appeared less pronounced, probably reflecting a larger pool of total $\mathrm{I} \kappa \mathrm{B} \alpha$, making the degradation more difficult to detect.

Further evidence of $\mathrm{NF} \kappa \mathrm{B}$ activation is indicated in Figure 3, showing the results of NF $\kappa \mathrm{B}$-DNA binding experiments by EMSA. Within 30 minutes, flagellin triggered a robust increase of NF $\kappa \mathrm{B}-\mathrm{DNA}$ binding, an effect that was particularly marked in the liver, with more than a 60 -fold increase compared with control conditions (Figure 3a). Interestingly, the positions of the shifted bands were different in the liver than in the other organs. As NF $\kappa \mathrm{B}$ is a family of heterodimeric (and homodimeric) proteins that include p50 (and its precursor p105), p52 (and its precursor p100), p65, RelB, and $c-$ Rel, this observation suggests that the composition of the $\mathrm{NF} \kappa \mathrm{B}$ dimer in the liver differs from the other organs. Given that the most common dimer is formed from a p50 and p65 subunit, we performed supershift experiments using anti-p50 and anti-p65 antibodies. As shown in Figure $3 \mathrm{~b}$, the bands were supershifted only by the anti-p65 antibody, implying that the NF $\kappa \mathrm{B}$ complex contains significant amounts of p65 in all organs exposed to flagellin. The liver disclosed an additional large shifted band, which did not supershift in the presence of anti-p50 and anti-p65, further supporting a distinct hetero-or homodimeric composition of $\mathrm{NF} \kappa \mathrm{B}$ in this organ. 


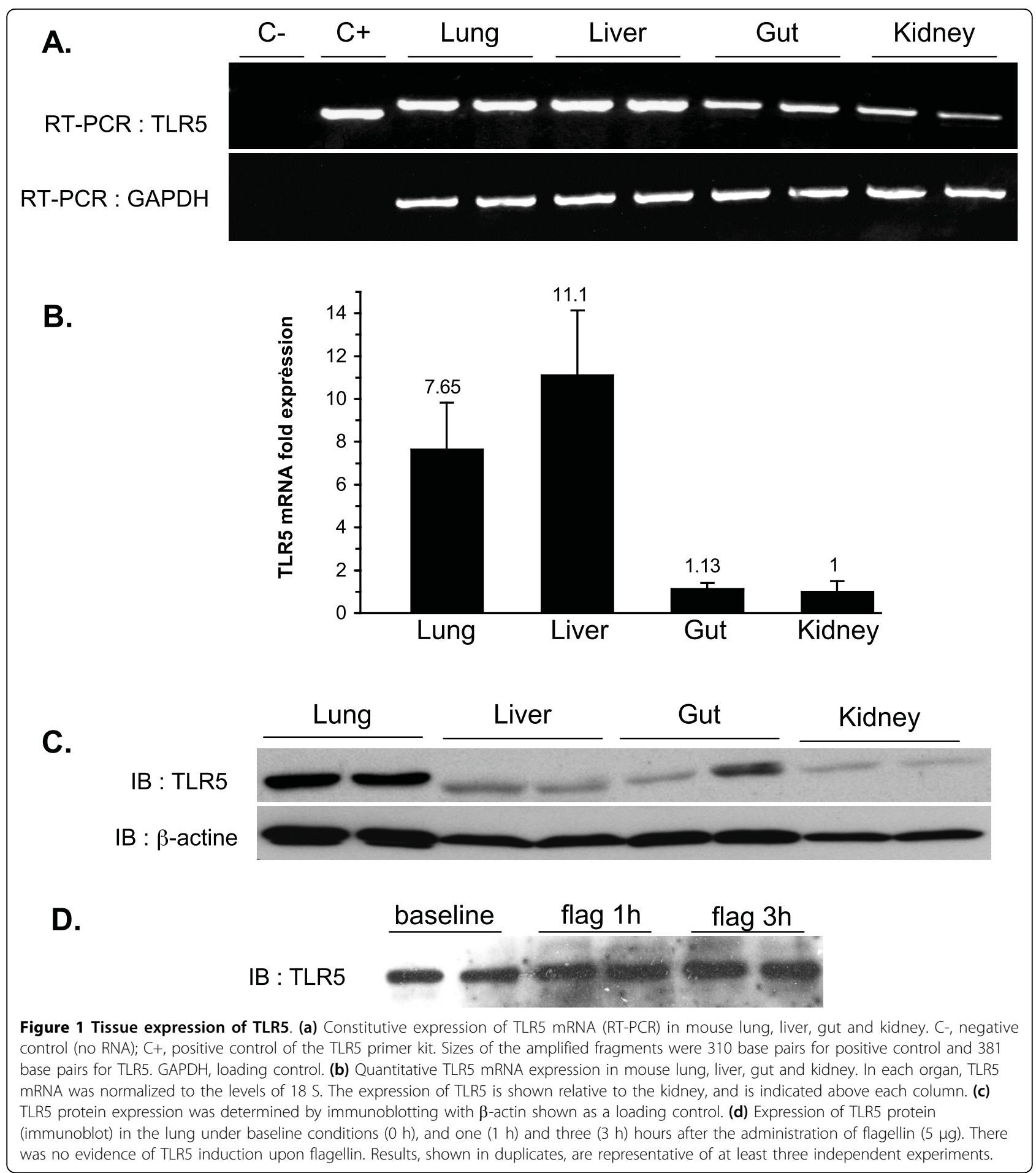

These findings are the first to formally demonstrate the ability of flagellin, at very low concentrations, to promote diffuse $\mathrm{NF} \kappa \mathrm{B}$ activation in vivo. It is noticeable that the degree of $\mathrm{NF} \kappa \mathrm{B}$ activation was the smallest in the lungs and intestines, which may indicate that organs naturally exposed to environmental micro-organisms have developed specific mechanisms to down-regulate TLR5-dependent signaling in order to prevent overwhelming and permanent inflammatory responses, an issue that should be addressed in future studies.

Besides NF $\kappa \mathrm{B}$, TLRs also signal through the MAPK cascade, especially the stress-activated protein kinase 


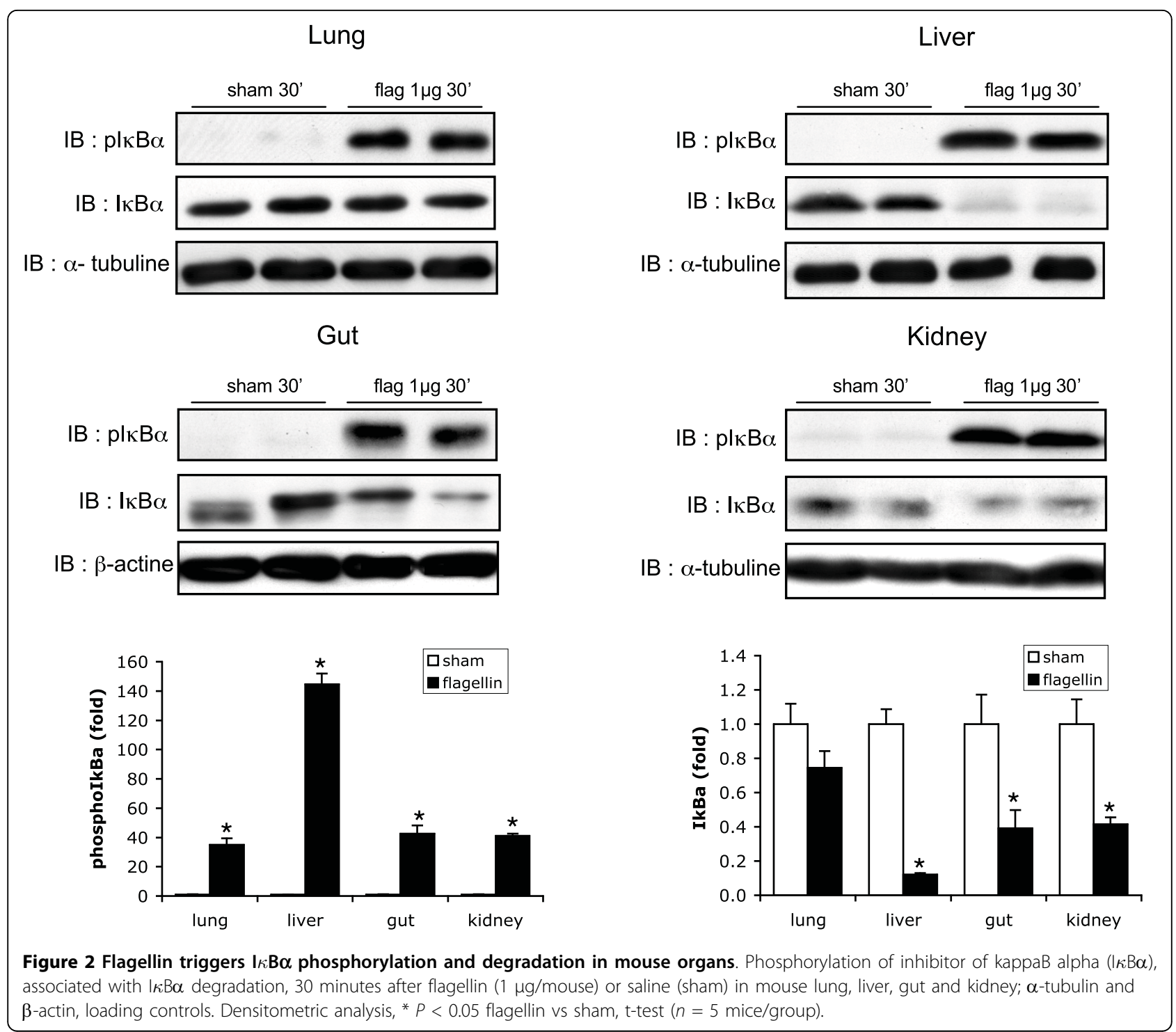

JNK and ERK [14]. Figure 4 shows that flagellin promoted strong phosphorylation of JNK in the lung and liver, contrasting with a weak activation in the gut and kidney. With respect to ERK, its phosphorylation was enhanced in the lung, gut and kidney, and less in the liver, in which ERK was already phosphorylated under baseline conditions. These novel observations point to significant organ specificity in the modulation of TLR5dependent signaling in response to flagellin, a feature also observed with other bacterial components triggering innate immune responses, such as peptidoglycan [15]. The mechanisms underlying such organ-specific responses cannot be determined from our current data and thus will need further investigations.

It is worth mentioning that an increase in the dose of flagellin to $5 \mu \mathrm{g} /$ mouse did not exert any further increase in the activation of MAPKs and $\mathrm{NF} \kappa \mathrm{B}$, as shown by a comparable degree of ERK and I $\kappa \mathrm{B} \alpha$ phosphorylation in the different organs (Figure 5), suggesting that minute doses of flagellin are already sufficient to produce a maximal activation of these stress signaling cascades. This observation is consistent with the marked pro-inflammatory potency of flagellin, which has been shown to induce a pro-inflammatory response in the lung at a threshold of $10 \mathrm{ng} /$ mouse [6]. A further finding was the transient nature of the process of immune activation triggered by flagellin, as indicated by the absence of sustained phosphorylation of ERK and $\mathrm{I} \kappa \mathrm{B} \alpha$ six hours after the injection of flagellin (Figure 5). This time-course is indeed typical of the usual short-lived pattern of MAPKs and NF $\kappa$ B activation due to the rapid induction of negative feedback regulatory mechanisms [5,16-18]. Such balance between immune activation and subsequent deactivation is critical to eliminate invading 


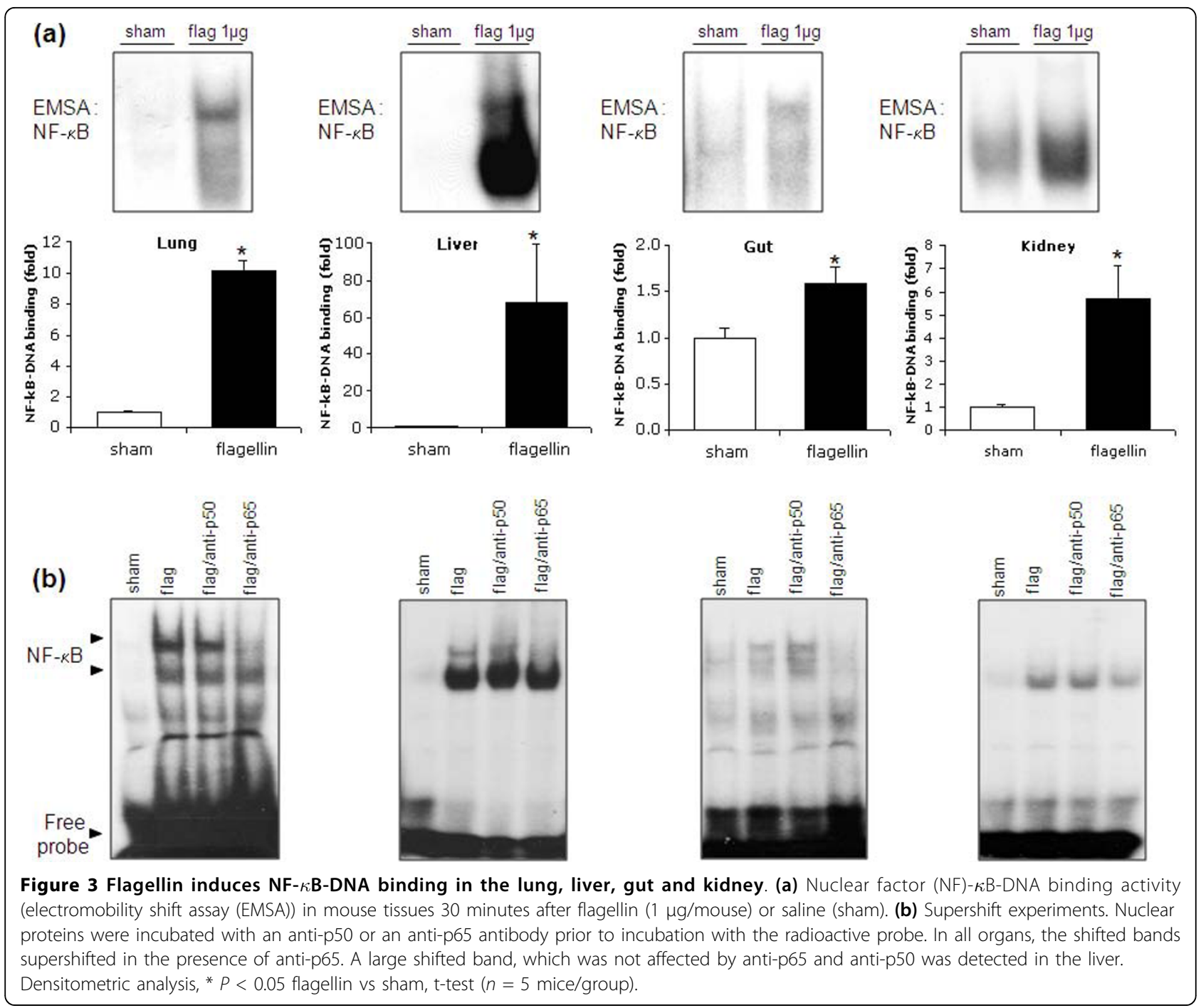

pathogens, while at the same time restraining the risk of self-destruction by unopposed inflammatory responses [18].

\section{Flagellin promotes widespread generation of inflammatory cytokines}

The activation of TLRs ultimately results in the enhanced expression of multiple inflammatory mediators [19], which stand at the foreground of the systemic inflammation and multiple organ dysfunction characterizing septic shock [20]. Accordingly, the activation of innate immune signaling by flagellin translated into the establishment of a pro-inflammatory phenotype in the organs examined, as shown by the up-regulated expression of the cytokines TNF $\alpha$, IL- $1 \beta$, IL- 6 , sTREM- 1 , and the chemokine MIP-2 (the rodent equivalent of human IL-8) in these organs (Figure 6), as well as in plasma (Figure 7), after flagellin administration. Similarly to the activation of $\mathrm{NF} \kappa \mathrm{B}$ and ERK discussed above, the rise in plasma cytokines (at least for TNF $\alpha$, IL-6 and MIP-2) was similar at 1 or $5 \mu \mathrm{g}$, further supporting the considerable pro-inflammatory potency of this bacterial protein. In spite of this diffuse inflammatory response, it is worth mentioning that the doses of flagellin used in this study were not lethal, as indicated by the lack of any mortality observed up to 48 hours after flagellin administration.

The production of cytokines followed two distinct time-courses. First, TNF $\alpha$, IL- 6 and MIP-2 in tissues showed an early peak after one hour and a steady decline thereafter, with a return to baseline concentrations at three hours (for TNF $\alpha$ and IL-6). A noticeable exception was the lung, in which IL-6 did not show any increase over time after flagellin, but it is noteworthy that the concentration of IL- 6 was already elevated under baseline conditions in this organ, an observation 


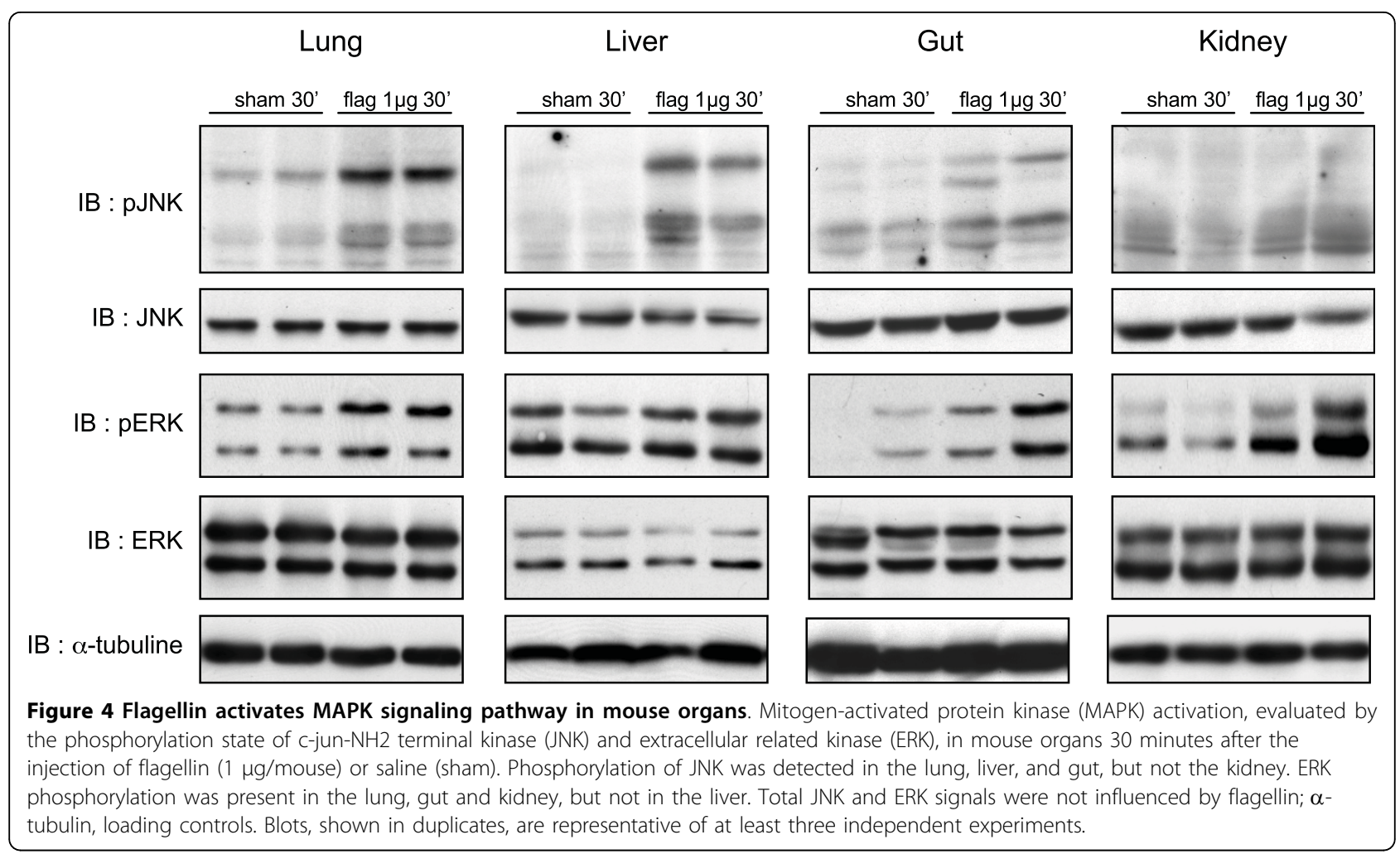

already reported by others $[21,22]$. In plasma, TNF $\alpha$ increased only transiently, with a peak at one hour followed by return to baseline values at later time-points. IL- 6 and MIP-2 also peaked after one hour, but were still significantly elevated at three and six hours. Such profile is comparable with the hyperacute cytokine response, which is observed following the administration of LPS both in animals [23] and humans [24].

A second, distinct time-course was observed for IL- $1 \beta$ and STREM-1, which remained elevated after three hours in the organs and were still significantly increased in the plasma six hours after the flagellin challenge. TREM-1, expressed at the surface of neutrophils and a subset of monocytes [25], is released as a soluble form in the plasma during sepsis and endotoxemia with a time-course similar to the one noted in the current study [26]. With respect to IL-1 $\beta$, it must be underscored that its expression does not rely on NF- $\kappa$ B signaling, but instead on the activation of caspase- 1 and inflammasome-dependent processing of pro-IL-1 $\beta$ [27]. Inflammasomes are high-molecular weight, caspase-1-activating platforms that control maturation and secretion of IL-1 $\beta$, which are assembled upon activation of intracellular receptors by various microbial and hostderived danger signals. These receptors belong to the

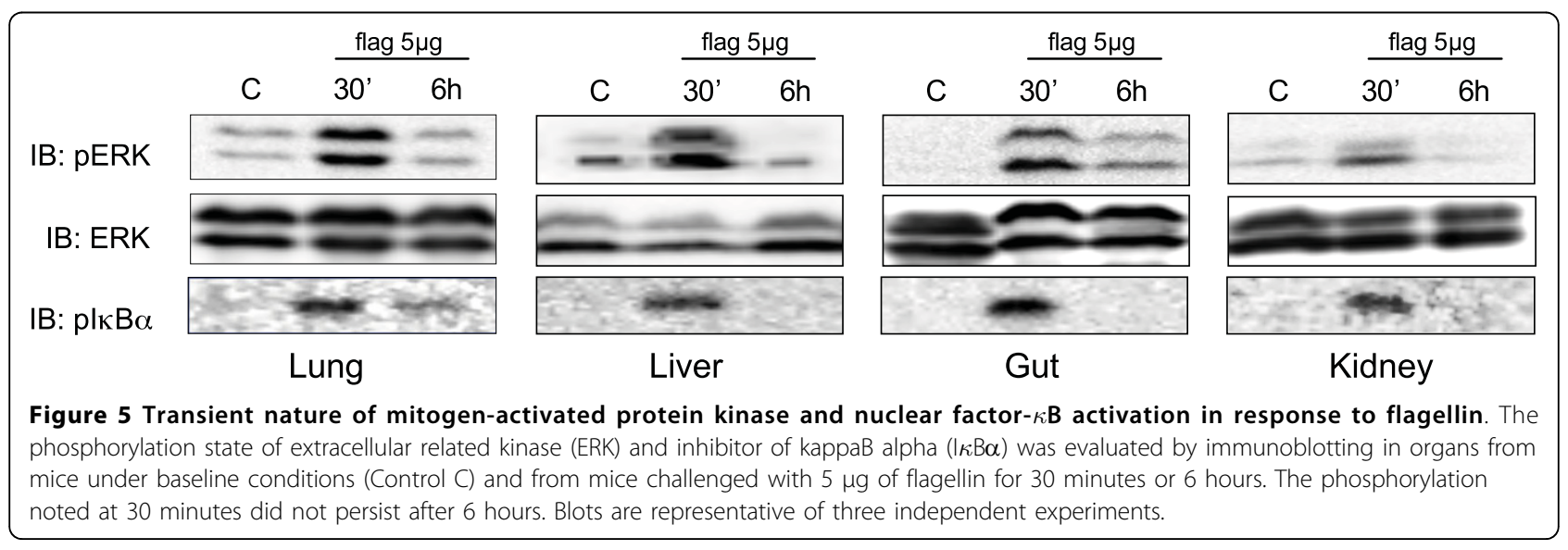




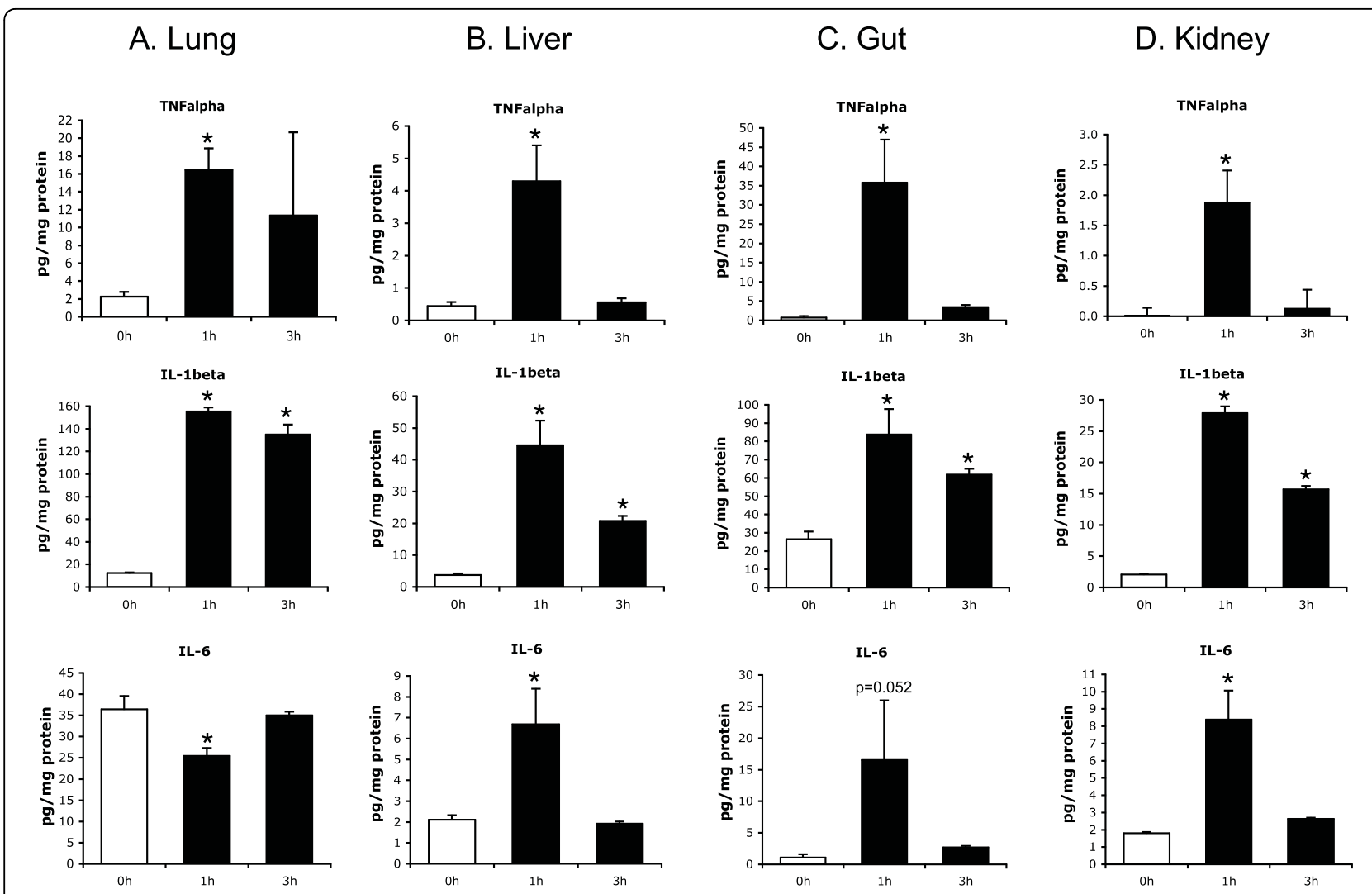

Figure 6 Flagellin triggers the diffuse expression of pro-inflammatory cytokines. Levels of inflammatory cytokines, measured by ELISA, in (a) lung, (b) liver, (c) gut and (d) kidney, at baseline and one and three hours after flagellin administration (5 $\mu \mathrm{g} / \mathrm{mouse}) .{ }^{*} P<0.05$ versus baseline (analysis of variance followed by Dunnett's test, $n=5$ to 6 mice/group).

nucleotide binding oligomerization domain (NOD)-like receptor family, consisting of the NODs, the NOD-like receptor proteins (NLRPs) and the interleukin-1-converting enzyme protease-activating factor (IPAF) subfamilies. The IPAF inflammasome is activated by cytosolic flagellin (in contrast to the recognition of extracellular flagellin by TLR5), which is injected into the cytosol via bacterial type III and IV secretion systems. The increased expression of IL-1 $\beta$ observed in our study is therefore consistent with the activation of the IPAF inflammasome by flagellin [28-30]. In summary, the time-course of the different cytokines reported in the current study support the concept that flagellin triggers an early, diffuse and transient proinflammatory response, that is followed by the activation of mononuclear cells, promoting a long-lasting secondary response characterized by persistent elevation of sTREM-1

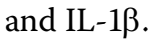

\section{Flagellin differentially triggers apoptotic signaling in mouse organs}

Multiple organ dysfunction in sepsis generally occurs in the absence of significant apoptosis or necrosis in the failing organs, except from the gut, in which extensive apoptosis of epithelial cells has been reported [31]. Apoptosis in the gut may be particularly detrimental in sepsis by compromising bowel wall integrity, as suggested by studies reporting significantly reduced sepsis mortality in transgenic mice overexpressing the antiapoptotic protein $\mathrm{Bcl}-2$ in their intestinal epithelium $[32,33]$. Here we sought to determine the ability of flagellin to initiate apoptotic signaling in mouse organs, by determining the degree of activation of capase-3, one of the major executioner caspases, and the cleavage of its substrate PARP [34].

As illustrated in Figure 8, flagellin triggered only transient caspase- 3 and PARP cleavage in the lung and liver, pointing to limited apoptosis and rapid clearance of apoptotic cells in these organs. In the kidney, except from a slight cleavage of PARP at one hour, apoptotic changes were virtually absent. These observations are totally consistent with the low degree of apoptosis reported in the liver, lung and kidney during sepsis [35]. In marked contrast, significant apoptotic changes were present in the gut, as indicated by a very strong cleavage 


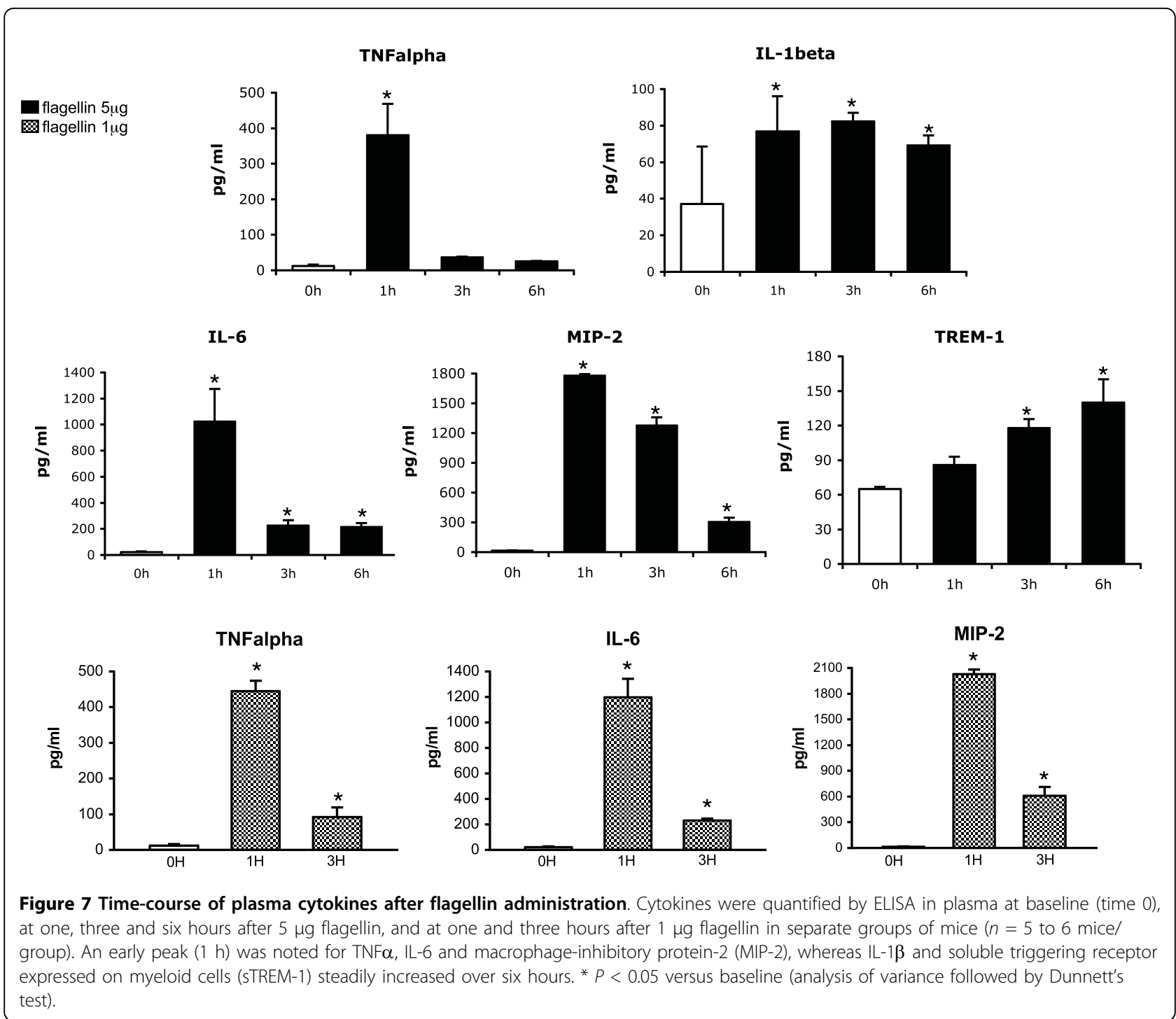

of both caspase- 3 and PARP, three hours after flagellin administration. It is particularly noteworthy that a previous study indicated that apoptosis within the gut during polymicrobial sepsis is endotoxin-independent [36]. Thus, our findings suggest that flagellin might represent an important culprit of these changes in this setting.

\section{Study limitations}

The different measurements in our study were performed at the level of whole organs containing multiple cell populations (parenchymal, vascular and inflammatory cells). Therefore, we cannot comment further on the respective implication of each of these cell types in the observed effects of flagellin. Further studies using histochemical labeling would be necessary to address this issue. A second limitation is the lack of direct comparisons between the effects of flagellin and endotoxin in our study. However, due to the extensive documentation of the effects of endotoxin in the murine model, we opted to focus primarily on the systemic effects of flagellin, which have remained so far largely unexplored. Thirdly, with respect to apoptosis, we only relied on molecular markers and thus, we cannot provide direct quantification of the severity of apoptosis in the different organs evaluated, which would require further immunohistochemical studies.

\section{Conclusions}

In conclusion, the data presented herein are the first to formally demonstrate that TLR5 is widely expressed in mouse organs in vivo, that flagellin elicits prototypical innate immune responses in these organs, and that it also activates apoptotic signaling, predominantly in the intestine. These findings imply that flagellin may be 


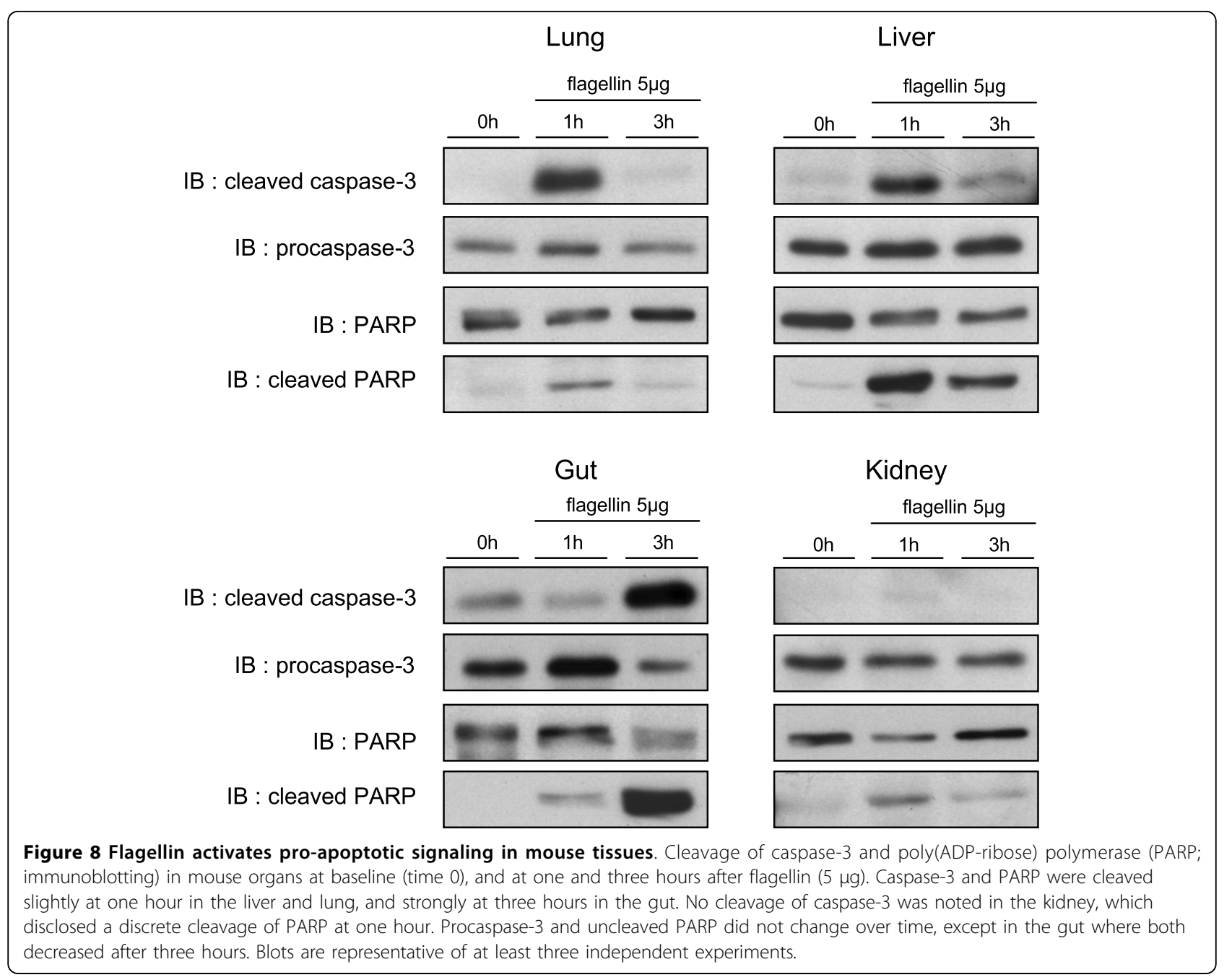

instrumental in the pathogenesis of Gram-negative sepsis. Hence, the therapeutic potential of anti-flagellin or anti-TLR5 strategies in this setting should be tested in the future.

\section{Key messages}

- TLR5, the specific mammalian receptor for bacterial flagellin, is expressed in the lung, kidney, liver and small intestine of mice, both at the mRNA and protein level.

- Recombinant Salmonella flagellin elicits widespread innate immune responses in mouse organs, characterized by the activation of NF- $\kappa \mathrm{B}$ and MAPKs.

- The innate immune response to bacterial flagellin promotes systemic inflammation and triggers apoptotic signalling in the intestine.

- Flagellin/TLR5 signaling may be instrumental in the pathogenesis of Gram-negative sepsis.

\section{Abbreviations}

ELISA: enzyme-linked immunosorbent assay; EMSA: electromobility shift assay; ERK: extracellular related kinase; $\mid \kappa B \alpha$ : inhibitor of kappaB alpha; IL: interleukin; JNK: c-jun-NH2 terminal kinase; LPS: lipopolysaccharide; MAPK: mitogen-activated protein kinase; MIP: macrophage-inhibitory protein; NF- $\kappa$ B nuclear factor kappaB; NLRP: NOD-like receptor protein; NOD: nucleotide binding oligomerization domain; IPAF: interleukin-1-converting enzyme protease-activating factor; PARP: poly(ADP-ribose) polymerase; PCR: polymerase chain reaction; STREM-1: soluble triggering receptor expressed on myeloid cells; TLR: toll-like receptor; TNF $\alpha$ : tumor necrosis alpha.

\section{Acknowledgements}

This work was supported by a Grant from the Swiss National Fund for Scientific Research (320000-118174/1) and a Grant from The Lausanne CardioMet Foundation (Nr 2007-R07-15) to Lucas Liaudet.

\section{Author details}

'Department of Intensive Care Medicine, University Hospital Medical Center and Faculty of Biology and Medicine, rue du Bugnon 46, Lausanne 1010, Switzerland. 'Division of Pathophysiology, Department of Internal Medicine, University Hospital Medical Center and Faculty of Biology and Medicine, Rue du Bugnon 46, Lausanne 1010, Switzerland. ${ }^{3}$ Laboratory of Physiologic Studies, National Institute on Alcohol Abuse and Alcoholism, National Institutes of Health, Bethesda, MD 20892-9413, USA. 


\section{Authors' contributions}

$J R, N L, S L, N R V$, and SRC performed the experimental work. LL, PP, and NRV contributed to the conception and design of the study. LL, FF, BW, and PP contributed to analysis of data, manuscript drafting and revising. LL obtained funding.

\section{Competing interests}

The authors declare that they have no competing interests.

Received: 18 February 2010 Revised: 16 June 2010

Accepted: 24 August 2010 Published: 24 August 2010

\section{References}

1. Roger T, Froidevaux C, Le Roy D, Reymond MK, Chanson AL, Mauri D, Burns K, Riederer BM, Akira S, Calandra T: Protection from lethal gramnegative bacterial sepsis by targeting Toll-like receptor 4. Proc Natl Acad Sci USA 2009, 106:2348-2352.

2. Daubeuf B, Mathison J, Spiller S, Hugues S, Herren S, Ferlin W, KoscoVilbois M, Wagner H, Kirschning CJ, Ulevitch R, Elson G: TLR4/MD-2 monoclonal antibody therapy affords protection in experimental models of septic shock. J Immunol 2007, 179:6107-6114.

3. Steiner TS: How flagellin and toll-like receptor 5 contribute to enteric infection. Infect Immun 2007, 75:545-552.

4. Hayashi F, Smith KD, Ozinsky A, Hawn TR, Yi EC, Goodlett DR, Eng JK, Akira S, Underhill DM, Aderem A: The innate immune response to bacterial flagellin is mediated by Toll-like receptor 5. Nature 2001, 410:1099-1103.

5. Eaves-Pyles T, Murthy K, Liaudet L, Virag L, Ross G, Soriano FG, Szabo C, Salzman AL: Flagellin, a novel mediator of Salmonella-induced epithelial activation and systemic inflammation: I kappa B alpha degradation, induction of nitric oxide synthase, induction of proinflammatory mediators, and cardiovascular dysfunction. J Immunol 2001, 166:1248-1260

6. Liaudet L, Szabo C, Evgenov OV, Murthy KG, Pacher P, Virag L, Mabley JG, Marton A, Soriano FG, Kirov MY, Bjertnaes LJ, Salzman AL: Flagellin from gram-negative bacteria is a potent mediator of acute pulmonary inflammation in sepsis. Shock 2003, 19:131-137.

7. Gewirtz AT: TLRs in the Gut. III. Immune responses to flagellin in Crohn's disease: good, bad, or irrelevant? Am J Physiol Gastrointest Liver Physiol 2007, 292:G706-710

8. Levrand S, Pesse B, Feihl F, Waeber B, Pacher P, Rolli J, Schaller MD, Liaudet L: Peroxynitrite is a potent inhibitor of NF-\{kappa\}B activation triggered by inflammatory stimuli in cardiac and endothelial cell lines. J Biol Chem 2005, 280:34878-34887.

9. Pesse B, Levrand S, Feihl F, Waeber B, Gavillet B, Pacher P, Liaudet L: Peroxynitrite activates ERK via Raf-1 and MEK, independently from EGF receptor and p21(Ras) in H9C2 cardiomyocytes. J Mol Cell Cardiol 2005, 38:765-775.

10. Nishimura M, Naito S: Tissue-specific mRNA expression profiles of human toll-like receptors and related genes. Biol Pharm Bull 2005, 28:886-892.

11. Rolli J, Levrand S, Waeber B, Feihl F, Liaudet L: Bacterial flagellin is a potent mediator of myocardial inflammation and cardiac dysfunction. Intensive Care Med 2007, 33:S35.

12. Rhee $\mathrm{SH}, \mathrm{Im}$ E, Riegler M, Kokkotou E, O'Brien M, Pothoulakis C: Pathophysiological role of Toll-like receptor 5 engagement by bacterial flagellin in colonic inflammation. Proc Natl Acad Sci USA 2005, 102:13610-13615.

13. Karin M: The IkappaB kinase - a bridge between inflammation and cancer. Cell Res 2008, 18:334-342.

14. Cinel I, Opal SM: Molecular biology of inflammation and sepsis: a primer. Crit Care Med 2009, 37:291-304.

15. Wang JE, Dahle MK, McDonald M, Foster SJ, Aasen AO, Thiemermann C Peptidoglycan and lipoteichoic acid in gram-positive bacterial sepsis: receptors, signal transduction, biological effects, and synergism. Shock 2003, 20:402-414.

16. Loukili N, Rosenblatt-Velin N, Rolli J, Levrand S, Feihl F, Waeber B, Pacher P, Liaudet $L$ : Oxidants positively or negatively regulate nuclear factor kappa B in a context-dependent manner. J Biol Chem 2010, 285:15746-15752.

17. Li X, Cui X, Li Y, Fitz Y, Hsu L, Eichacker PQ: Parthenolide has limited effects on nuclear factor-kappa beta increases and worsens survival in lipopolysaccharide-challenged C57BL/6J mice. Cytokine 2006, 33:299-308.
18. Zhao Q, Wang X, Nelin LD, Yao Y, Matta R, Manson ME, Baliga RS, Meng X Smith CV, Bauer JA, Chang CH, Liu Y: MAP kinase phosphatase 1 controls innate immune responses and suppresses endotoxic shock. J Exp Med 2006, 203:131-140

19. Kawai T, Akira S: The roles of TLRs, RLRs and NLRs in pathogen recognition. Int Immunol 2009, 21:317-337.

20. Russell JA: Management of sepsis. N Engl J Med 2006, 355:1699-1713.

21. Imai Y, Kuba K, Neely GG, Yaghubian-Malhami R, Perkmann T, van Loo G, Ermolaeva M, Veldhuizen R, Leung YH, Wang H, Liu H, Sun Y, Pasparakis M, Kopf M, Mech C, Bavari S, Peiris JS, Slutsky AS, Akira S, Hultqvist M, Holmdahl R, Nicholls J, Jiang C, Binder CJ, Penninger JM: Identification of oxidative stress and Toll-like receptor 4 signaling as a key pathway of acute lung injury. Cell 2008, 133:235-249.

22. Savale L, Tu L, Rideau D, Izziki M, Maitre B, Adnot S, Eddahibi S: Impact of interleukin-6 on hypoxia-induced pulmonary hypertension and lung inflammation in mice. Respir Res 2009, 10:6.

23. Kotanidou A, Xagorari A, Bagli E, Kitsanta P, Fotsis T, Papapetropoulos A Roussos C: Luteolin reduces lipopolysaccharide-induced lethal toxicity and expression of proinflammatory molecules in mice. Am J Respir Crit Care Med 2002, 165:818-823.

24. Mayr FB, Spiel AO, Leitner JM, Firbas C, Kliegel T, Jilma-Stohlawetz $P$, Derendorf $\mathrm{H}$, Jilma B: Duffy antigen modifies the chemokine response in human endotoxemia. Crit Care Med 2008, 36:159-165.

25. Opal SM, LaRosa SP: Year in review 2008: Critical Care-sepsis. Crit Care 2009, 13:224.

26. Gibot S, Kolopp-Sarda MN, Bene MC, Bollaert PE, Lozniewski A, Mory F, Levy B, Faure GC: A soluble form of the triggering receptor expressed on myeloid cells-1 modulates the inflammatory response in murine sepsis. $J$ Exp Med 2004, 200:1419-1426.

27. Greten FR, Arkan MC, Bollrath J, Hsu LC, Goode J, Miething C, Goktuna SI, Neuenhahn M, Fierer J, Paxian S, Van Rooijen N, Xu Y, O'Cain T, Jaffee BB, Busch DH, Duyster J, Schmid RM, Eckmann L, Karin M: NF-kappaB is a negative regulator of IL-1 beta secretion as revealed by genetic and pharmacological inhibition of IKKbeta. Cell 2007, 130:918-931.

28. Schroder K, Tschopp J: The inflammasomes. Cell 2010, 140:821-832.

29. Franchi L, Eigenbrod T, Munoz-Planillo R, Nunez G: The inflammasome: a caspase-1-activation platform that regulates immune responses and disease pathogenesis. Nat Immunol 2009, 10:241-247.

30. Miao EA, Andersen-Nissen E, Warren SE, Aderem A: TLR5 and Ipaf: dual sensors of bacterial flagellin in the innate immune system. Semin Immunopathol 2007, 29:275-288.

31. Hotchkiss RS, Nicholson DW: Apoptosis and caspases regulate death and inflammation in sepsis. Nat Rev Immunol 2006, 6:813-822.

32. Coopersmith CM, Chang KC, Swanson PE, Tinsley KW, Stromberg PE, Buchman TG, Karl IE, Hotchkiss RS: Overexpression of Bcl-2 in the intestinal epithelium improves survival in septic mice. Crit Care Med 2002, 30:195-201.

33. Coopersmith CM, Stromberg PE, Dunne WM, Davis CG, Amiot DM, Buchman TG, Karl IE, Hotchkiss RS: Inhibition of intestinal epithelial apoptosis and survival in a murine model of pneumonia-induced sepsis. JAMA 2002, 287:1716-1721.

34. Levrand S, Vannay-Bouchiche C, Pesse B, Pacher P, Feihl F, Waeber B, Liaudet $L$ : Peroxynitrite is a major trigger of cardiomyocyte apoptosis in vitro and in vivo. Free Radic Biol Med 2006, 41:886-895.

35. Hotchkiss RS, Swanson PE, Freeman BD, Tinsley KW, Cobb JP, Matuschak GM, Buchman TG, Karl IE: Apoptotic cell death in patients with sepsis, shock, and multiple organ dysfunction. Crit Care Med 1999, 27:1230-1251.

36. Hiramatsu M, Hotchkiss RS, Karl IE, Buchman TG: Cecal ligation and puncture (CLP) induces apoptosis in thymus, spleen, lung, and gut by an endotoxin and TNF-independent pathway. Shock 1997, 7:247-253.

\section{doi:10.1186/cc9235}

Cite this article as: Rolli et al: Bacterial flagellin elicits widespread innate immune defense mechanisms, apoptotic signaling, and a sepsislike systemic inflammatory response in mice. Critical Care 2010 14:R160. 